\title{
THE GENITIVE CASE AS A GRAMMATICAL PREFERENCE OF MODERN PRESS
}

\author{
Marina A. Salkova \\ bestgrammar@yandex.ru \\ Olga A. Machina
}

Moscow State Linguistic University (Moscow, Russia)

\begin{abstract}
The article focuses on the construction N's $+\mathrm{N}$ known as the genitive case structure. Analysis of the data retrieved from two English Language corpora (the BNC and COCA) has demonstrated that the N's $+\mathrm{N}$ structure as a typical grammatical feature of modern mass media discourse realizes certain communicative and discursive properties that constitute the core of this mixed morphological-and-syntactic phenomenon. Thanks to its anthropocentric character, the structure also possesses some functional capacities that make a valuable and indispensable contribution to the organization of meaning in mass media texts.
\end{abstract}

Key words: media discourse; corpus-based analysis; grammar rule; the genitive case.

\section{INTRODUCTION}

The role of mass media in modern society is substantial, and their language has become a pattern of modern linguistic practices. It is understood that the language of mass media has its own specific features, which relates not only to the lexis, but to grammar as well. Therefore, very often the media way of presentation serves as the main trigger and source of language innovations; it may also shape certain preferences that make this or that language structure more welcome into discussion of facts deserving public attention.

The aim of this article is to explore the use of nominal structures built according to the N's + N pattern, otherwise referred to as the construction with a noun in the genitive case or the genitive case structure. To be more precise, the following tasks are set:

1. to verify the rule prescribing the use of a limited number of semantic groups of nouns in the N's $+\mathrm{N}$ structure with the help of the statistical data based on a large corpus of British and American samples of speech related to different genres, namely the British National Corpus (BNC) and The Corpus of Contemporary American English (COCA);

2. to define semantic and discursive preferences in the use of nouns in this structure;

3. to explore the conditions governing the choice of the N's $+\mathrm{N}$ structure in mass media texts;

4. to offer interpretation to the observed language facts.

5. With regard to language teaching practice, the article also sets another subsidiary aim: it seeks to prove that corpora should become English language learners' everyday tool improving their language awareness and advanced linguistic perception.

\section{MATERIAL AND METHODS}

Addressing corpus data (the BNC and COCA) was a conscious choice granting relevance of the quantitative and qualitative observations made. Quantitative corpus based analysis has been carried out to acquire statistics concerning the choice and distribution of individual nouns/ semantic groups of nouns for the N's $+\mathrm{N}$ structure. Functional purpose- 
oriented analysis supported by broad philological interpretation of contextual facts has made it possible to expose the discursive properties of the grammatical phenomenon, including its variation (collocation and synonymy with the related $\mathrm{N}+$ preposition $o f+\mathrm{N}$ structure).

\section{STUDY AND RESULTS}

Describing the genitive (or, otherwise, possessive) case, grammars usually focus on the discussion of the status of its formant 's, which can be viewed as a case inflection [Greenbaum, 1996; Biber et al., 1999; Huddlestone \& Payne, 2002] or a post-positional element [Vorontsova, 1960; Quirk et al., 1985] / clitic, governed by the same syntactic rules as independent words [Carstairs-McCarthy, 2002].

As for the meaning, traditionally, the N's $+\mathrm{N}$ construction is associated with the expression of possession, where N's indicates the possessor and $\mathrm{N}$ denotes something possessed. Consequently, transformational-generative grammar suggests transforming such combinations into the kernel sentence " $\mathrm{N}$ has (possesses) $\mathrm{N}$ ", for example, John's cat corresponds to John has (possesses) a cat. However, a careful investigation of the structure's semantics shows that it is not limited to possession and includes many more meanings [Barkhudarov, 2009], the most prominent being:

- The subjective genitive, where Mother's advice corresponds to Mother gave advice;

- The objective genitive, where the criminal's arrest matches the criminal was arrested further transformed into someone / the police arrested the criminal;

- The adverbial genitive, where an hour's absence stands for an absence for one hour, two miles' distance is equivalent to the distance of two miles;

- The genitive of equation, where an arm's length means the length of an arm);

- The genitive of destination, where children's service correlates with service for children);

- The genitive of authorship, where Burns' poems covers the idea that Burns wrote poems, i.e. Burns is the author of poems;

- The attributive or qualitative genitive, where a woman's voice implies a voice that sounds womanlike. (This particular meaning has a very broad scope and allows a wide-ranging interpretation of the semantics of structures difficult to define unambiguously)

Closely connected with the possible meanings of the structure is the question about the semantic classes of nouns that can be used in the genitive (or, more traditionally, possessive) case form. Practical prescriptive grammars hold that the genitive case is a form associated with animate nouns on the semantic grounds that the possessor, the agent (subject) and the patient (object) in the corresponding constructions can be only animate relating inherently with the pronouns he, she, they, who. However, a few other structures do not presuppose such firmly fixed semantic connection. So, advanced grammars often include in the above mentioned list nouns denoting names of geographic and astronomical objects (Russia's poet, the sun's rays), collective nouns (the committee's decision), set phrases referring to measurement of time and distance (three hours' walk). They also mention the possibility of adding the morpheme - 's to a word group (the Head of the Parliament's speech) alongside the indefinite pronouns (like somebody, someone and one) (see, for example, [Gordon \& Krylova, 1986; Swan, 1995; Reznik et al., 1999].

Authors of theoretical descriptive grammars point to the opposition of the genitive and common cases. It is suggested that the genitive case always demonstrates some individual feature of the designated object, whereas the common case denotes a feature of a general 
character not related to a concrete bearer ${ }^{1}$, or, in other words, marks the nominative meaning opposed to the attributive one [Ivanova et al., 1981]. The opposition 'individual - general' explains the fact that the form of the genitive case is mainly applied to concrete personal (animate) nouns, while the use of the common case with the same nouns will create a "detaching" effect, a kind of alienation, leading to the appearance of such word combinations as the Pushkin Fine Arts Museum.

At the same time, theoretical grammars acknowledge cases where clearly inanimate nouns occur in the form of the genitive case (the wood's edge, a word's history), though this fact is not usually discussed furthermore. The authors of such theoretical investigations only point to the fact that the word groups like the car's roof hardly describe the individual properties of these objects but rather the construction part of the car known to the communicants from the preceding context or discussed in the general sense.

This objective deficiency of explanation claims for a more detailed study and better exemplification provided by corpora.

Within the framework of our brief investigation, the query to the BNC brought the following results.

Out of 100 words, most frequently used in the construction with the Genitive case, the majority (51\%) belongs to the class of animate nouns, both proper names and common nouns, the most numerous being the word "people" (used in 5383 cases). The form people's is especially frequent in such combinations as people's things / attention / requests / wages and is used equally often in texts of different genres. This means that the form people's is similarly typical of everyday speech and formal written texts.

The other semantic groups of nouns that occurred in the Genitive case form can be classified as follows:

1. among the names of geographical objects (19\%) the most frequent are the words Britain, country, world, London, England, city;

2 . the group of collective nouns (17\%) is headed by the words government, company, council, party, group, society;

3. the names of temporal periods $(6 \%)$ are represented by such words as year, week, day, month, night, Saturday;

4. among the inanimate nouns (5\%) the most popular words are school, club, bank, industry, life;

5. astronomical objects (2\%) comprised such nouns as sun and earth.

The border between groups 2 and 4 may seem vague enough because of the double semantic nature of the majority of words comprising the cluster of collective nouns. They are known to denote inanimate objects as well as an assembly of people united by a certain institution. In order to separate one from the other, we have conducted a semantic analysis of the examples provided by the corpora, specifically attesting the presence / absence of the seme "animacy" in the collective nouns. Our study has proved that in the nouns that we have referred to the class of "inanimate objects" this seme is absent. Consider the following example (all the given examples come from the BNC and COCA):

a. West Ham supporters are being urged to stage a second half walk-out during the match against Southampton on Tuesday night in the continuing protest at the club's bonds debenture scheme (The Daily Telegraph). - The club is spoken of as an organization dedicated to a particular activity.

Such nouns are used in the genitive case in a non-collective meaning, though alternative examples are also present in the studied corpus:

\footnotetext{
${ }^{1}$ Meanwhile, if used in the qualitative meaning, the nouns in the genitive case will acquire an undisputedly descriptive force (cf. the mother's letter vs a mother's instinct, Mother's Day).
} 
b. Manager Joe Kinnear, robbed of injured ace striker John Fashanu, sees Sheffield United's cult hero Corky as the vital replacement to ease the club's injury problems. Cork, Wimbledon's record busting striker, left reluctantly after 12 glorious years and immediately won the hearts of the Yorkshire club's fans (The Daily Mirror). In these sentences, the word $c l u b$ is used in the meaning of an association of people that play a certain sport together, i.e. that are sport celebrities not incidentally exposed to physical trauma, ageing, seeking career growth, etc. Therefore, the noun club expresses a collective meaning.

We made similar observations for other nouns that we primarily referred to the group of collective ones, such as firm, company, university, as shown by the following examples:

a. Factory workers fed-up with secretary Carolyn Bullock's dodgy parking hoisted her car on to the firm's roof with a crane (The Daily Mirror). - The noun firm here denotes a building.

b. [...] boxing and jogging two miles a day around the Crystal Harmony, the CocaCola company's flagship in Barcelona harbor (The Daily Mirror). - The word company is associated with construction.

c. If plant life is killed off, the eco-system could be permanently damaged, said Dr Murphy, of the University's Centre for Research in Environmental Science and Technology (The Belfast Telegraph). - In this sentence, the word university has a clear connection to organizations conducting research.

In the following examples, the nouns firm, company, university have a clearly animate reading, which is proved by their combinability with the words "failure", "concern", "claim":

a. They follow the firm's failure to win any of the last Type 23 frigates from the Ministry of Defence, or any substitute work despite a worldwide search (The Daily Mirror).

b. The company's prime concern is that when the collection is launched it is utterly free from criticism by even the most rigorous green scientists (The Daily Telegraph).

c. He denies the university's claim that he cheated in two papers through having advance knowledge of the questions (The Guardian).

We have got similar results from our query to the Corpus of Contemporary American English (COCA).

Out of 100 words that occur most commonly in the form of the genitive case $50 \%$ sharp represent animate nouns. The remaining 50\% comprise the following semantic groups:

1) geographical objects $(21 \%)$;

2) collective nouns (11\%), containing such words as family, nation, administration, court etc. (hereby come the same nouns as were included in this group according to the $\mathrm{BNC}$ );

3) inanimate objects (8\%) like company, agency, ship, area, body (as well as the nouns from the BNC);

4) nouns denoting temporal periods $(6 \%)$;

5) astronomical objects (2\%);

6) nouns, equally frequent in inanimate and collective meanings (2\%) - team and league (both are used as sport terms for people's groupings and in the meaning of inanimate objects, i.e. organizational structures).

The corpora allowed us to make another curious observation. We have noticed that such nouns, unambiguously treated as inanimate, as show, system, museum, center, car, program, park, baseball, film, game, book, water, house commonly occur in the genitive case form, for example: 
a. The bulk of the problems drivers reported were related to car technology (like getting your smartphone to pair with the car's Bluetooth) (USA Today).

$b$. One of the book's most persistent, recurrent themes, a shuttle that flies through the loom, is that black progress is always met with a violent backlash - the modern apotheosis of which was the election of Donald J. Trump's (The New York Times).

c. Why not give the game's most attractive selling points the chance to exhibit themselves as much as possible? (The New York Post).

At the same time, it seems rather peculiar that in the list of nouns affordable in the genitive case there are no names of animals, though the latter are strictly associated with animacy. Thus, it can be inferred that the pragmatic perception of this feature contradicts the accepted linguistic practice. The only noun among the first 200 words registered in this form in the COCA was the word $\operatorname{dog}$ that occupied 152 (sic!) position.

The corpus data also testify to the discursive inequality in the use of N's $+\mathrm{N}$ structure in both regional varieties of the English language. This construction is most frequent in the mass media written styles: newspapers and magazines (especially if taken together), followed by academic prose and fiction literature. This form is practically three times rarer in the samples of spoken language. The discursive diversity of N's $+\mathrm{N}$ structure is demonstrated by the charts:

Chart 1. The frequency of N's $+N$ structure by genres $(B N C)$

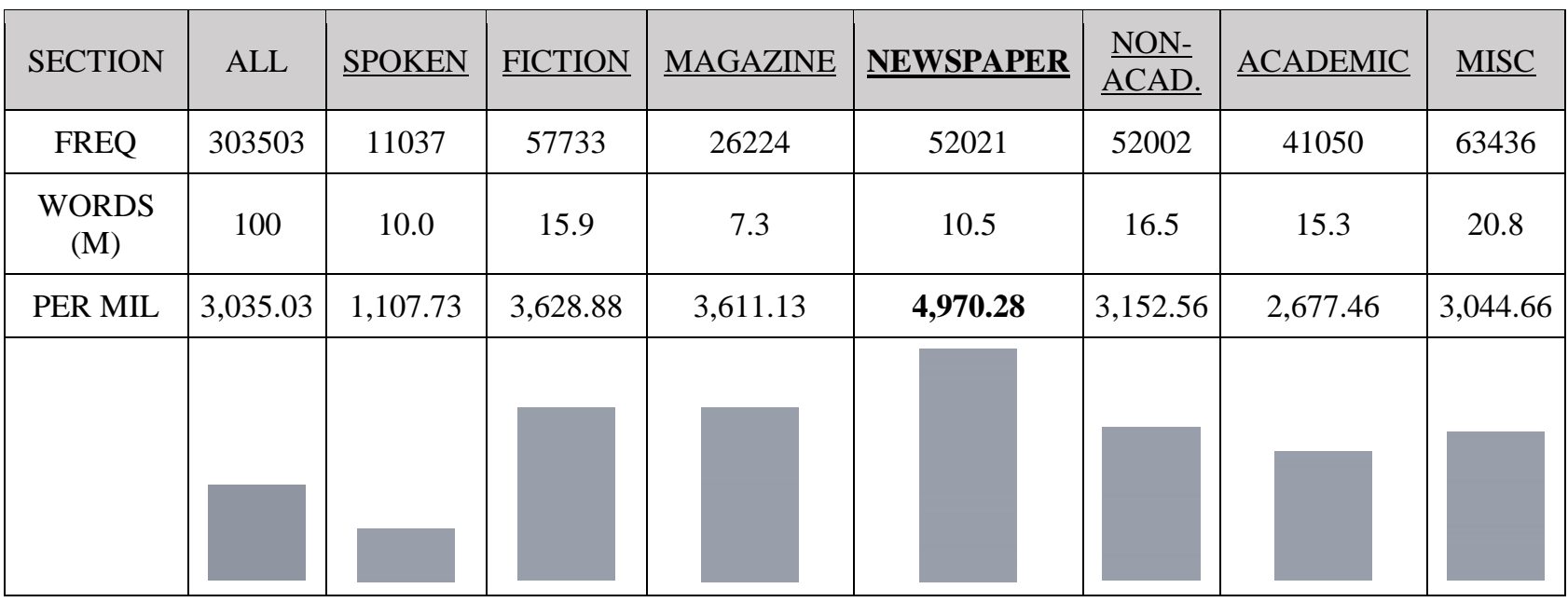

Chart 2. The frequency of $N$ 's $+N$ structure by genres (COCA)

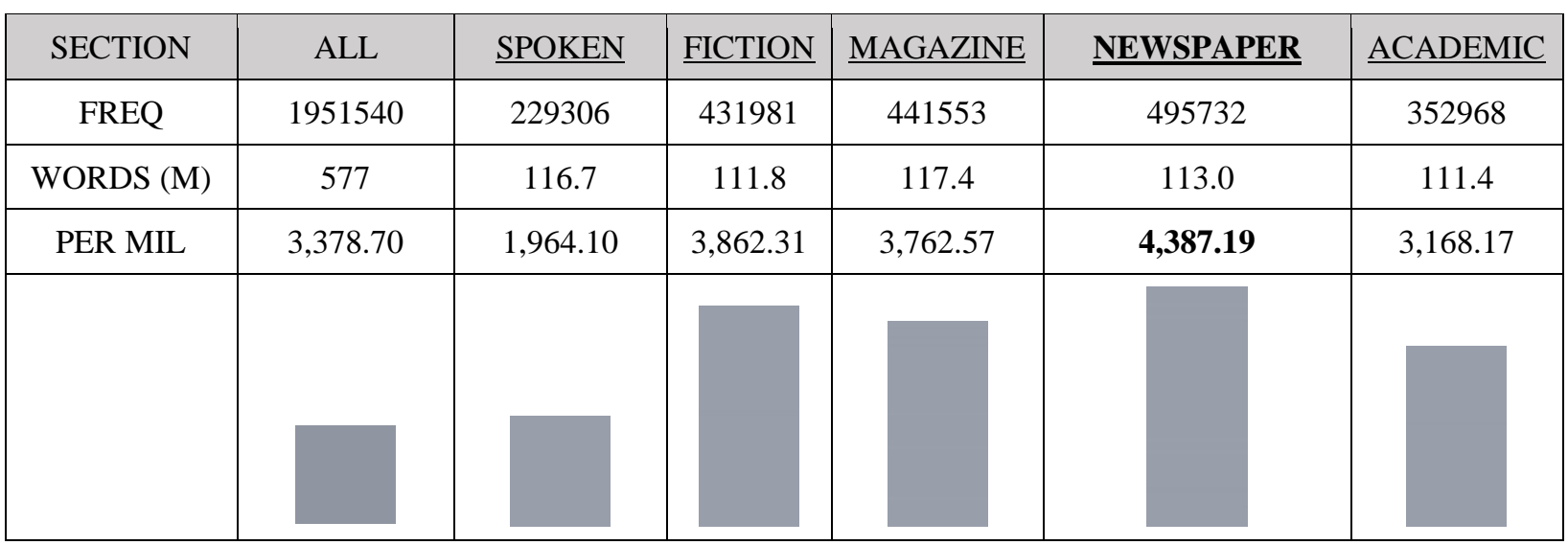




\section{DISCUSSION}

The semantic sphere covered by the nouns frequently occurring in the genitive case testifies to the strong anthropocentric character that this form has developed in present-day discourse: practically, all the nouns that are most frequent in this morphological form are related to human life and activity. Therefore, widespread use of animate and collective nouns, names of geographical objects and temporal periods appears only natural. The headlines of British and American news stories and featured sections at the news agencies' websites can serve as examples:

a. China's history of extraordinary rendition (bbc.com);

b. England's big picture: sharing images of the nation (bbc.com);

c. Trump's problem isn't Mexico. It's Central America, and it's getting worse (cnn.com);

d. U.S. Escalates Online Attacks on Russia's Power Grid (nytimes.com).

Speaking of nouns with ambiguous socially sensitive meanings, contextual analysis of the examples has lead us to the following deduction: despite the "inanimate object" semantics, there are no restrictions applied to the formation and use of the genitive case of such words. This testifies to the fact that when it comes to the choice between the synonymous N's $+\mathrm{N}$ and $\mathrm{N}+\operatorname{prp}(\mathrm{of})+\mathrm{N}$ constructions, the leading role in the author's decision belongs not to minor grammatical nuances of the noun but rather to other factors. On the one hand, the form itself may be seen as constructed due to the "form-building inertia": here it grounds the habit of using the genitive case of a lexical unit that in different contextual conditions may express a collective meaning or not. On the other hand, the principle of form-building inertia positively perceived is the reverse of the analogy (or economy) principle. In such perspective, it makes the genitive case form discursively popular as it literally jams the text and fills it with details without overloading the syntactical structure and destroying the information flow dynamism.

In the latter case, used as an attribute in the preposition to the head noun the genitive case noun keeps the main word highlighted and ensures its rhematic function. Alternatively, as the possible synonym of the N's + N structure the prepositional of-phrase occurring after the headword attracts more attention than the head, thus becoming the rheme of the sentence itself. Compare two examples from the COCA:

a. Top US officials announced President Trump's strategy on North Korea (The New York Post);

b. He insisted on keeping the decision to use nuclear arms in the hands of the president - seemed like a good idea at the time - and proclaimed in his farewell address, "Starting an atomic war is totally unthinkable for rational men" (The New York Times).

Thus, the N's $+\mathrm{N}$ in $a$. lets the reader focus their attention on the object rather than on its obvious possessor, while in $b$. it is the possessor that must be foregrounded as an state's official charged with the highest responsibility ever possible.

To illustrate our assumptions we will provide the text devoted to the story of the famous monument to the Little Mermaid in Copenhagen, Denmark. The monument repeatedly became the object of vandals who caused damage to it making different claims. As described in the article, the Little Mermaid suffered from the radical animal welfare advocates who spilt red paint all over it thus symbolizing their protest against the killing of Faroe Island's black whales. The Mermaid's mythological history is moved to the foreground, the alleged savagery and bloodthirstiness of her species supplant the original pathetic mission of the Anderson's tale character - to remind people of the power of true love.

The Vandalized Little Mermaid. By Kelly Grovier, 2 June 2017 Spare a thought for The Little Mermaid. In the 104 years since the Danish-Icelandic sculptor Edvard Eriksen created his bronze statue of a young half-woman half-fish [...] the $1.25 \mathrm{~m}$ (4.1ft) tall sculpture 
has been decapitated twice, bludgeoned in the neck..., dismembered, defaced with luminous paint [...], and blown off her base by a bomb [...] Eriksen's sculpture was, from the first, forged in violence. It is inspired by the Danish writer Hans Christian Andersen's unsettling tale of a lovestruck mermaid who is so desperate to gain an eternal human soul that she sacrifices to a Sea Witch her tongue, her mellifluous voice and her ability ever to return to her underwater home. The head and face are those of a ballerina, Ellen Price (who declined to model nude for the sculptor), which have been grafted onto the naked physique of Eriksen's wife, Eline. The result is a work of enforced fusion, one that seems forever to hover on a hazy margin between states of being - fact and fantasy, hope and harm, this world and another. The many levels of The Little Mermaid's disturbed and disturbing identity were brought to mind this week with the emergence in the news of a fresh image of assault that the statue suffered on the 30 May, this time at the hands of anti-whaling activists. Protesting against the hunting of long-finned pilot whales in the North Atlantic, vandals doused Copenhagen's unofficial mascot in red paint and scrawled along the pavement nearby the plea "Danmark [sic] defend the whales of the Faroe Islands". Beneath the veneer of red paint, the statue's bronze surface burns through, giving the work a lustrous haemoglobin glow, as if the mermaid were herself drenched in blood. Under a veil of vandalism, the hybrid creature can be perceived as both the perpetrator and the victim of the violence - an eerie ambiguity that transforms Eriksen's statue from a totem of fairytale wonder into something haunting and ominous. In its defaced state, the statue's gruesome complexion calls to mind the legend of sirens who lure boatmen to their doom with their seductive song. Long before Andersen enchantingly reinvented the mermaid in the 19th Century, eliciting sympathy from his readers for her tragic fate, a more lethally enticing incarnation of the creature troubled the imagination of readers of a lavish 13th Century bestiary - or illustrated compendium of real and fabled beasts.

Created by a medieval English artist whose name has since faded into the fog of history, the image of a fish-woman sinisterly singing to sailors who try desperately to plug their ears, is among the more intriguing illustrations in the volume. Inauspiciously, the sepiasoaked sky surrounding the mortal figures appears clotted with blood. That one of the grimfaced sailors is clad in blood-red attire and weakly clings to a blood-red oar, does not bode well for their survival. Placed alongside this week's photo of the defaced Little Mermaid of Copenhagen, the ancient illustration reveals just how deep the symbol of the mermaid has dived into the cultural imagination [The Vandalized Little Mermaid, 2017].

Let us analyze the grammatical facts observed in the article. There are nine structures with the nouns in the genitive case in it, five of them are animate and four are inanimate ones. Among the first we identify four cases of the use of proper names (Andersen's, Eriksen's) and a word group that is contextually close to them (The Little Mermaid). Therefore, the ratio of hereby represented nouns is close to the one we observed in the studied corpora $(55 \%$ vs $45 \%$ ). Among the nouns of the second group, we have traced the word statue, denoting an inanimate object (used twice), the geographical name Copenhagen and the noun week with the temporal semantics. Therefore, this group of nouns shows the proportion of different meanings of inanimacy approximately corresponding to the corpus data.

It is also notable that the inanimate noun statue shows different implications depending on the change of the author's outlook throughout the story. The word is conceptually close to the word people through the idea of the imitation of a human image in a work of art, and therefore in the first part the statue of the Little Mermaid is practically animate, her touching story evoking the author's and the audience's sympathy. Later the vandalized statue is presented as a lifeless figure, a symbol of brutality. This fact, however, does not prevent the author from employing the form of the genitive case. 


\section{CONCLUSIONS}

The mixed traditional and more modern corpus based methodology used in this article appears satisfactory to obtain the desired goals.

The use of the N's $+\mathrm{N}$ structure may be placed among the lexical-and-grammatical phenomena claimed by modern mass media for a number of reasons. In our opinion, the observed discursive preferences for the use of nouns in the genitive case have three main reasons.

Primarily, it must be stated that the grammatical rule remains true of modern English language practice though of late, the use of N's $+\mathrm{N}$ has shown a somewhat limited character of its textbook description. It is now fair to say that the semantic fields of nouns used in the genitive case thematically conform to the information scope of professional journalistic discourse, with mass media texts covering events in different parts of the globe mostly with people's participation. With regard to grammar, the historical processes we witness and register in linguistic realia have made users revise the traditional rule. As a result, the animacy restriction has become less rigid and may continue to fade with time. It is hardly possible to predict any radical change to the established norm but there is little doubt that more nouns will be used in the genitive case for it is relation to man's social activity, i.e. possession and subjectivity that is decisive rather than abstract semantic classification of words.

Secondly, the N's + N structure suits the task of compact and concise information presentation mode, and linguists do not exaggerate when they relate language economy to the speed of information flow, which has always been crucial for journalism.

Connected with it is the third reason, namely the communicative function of the noun in the genitive case. Making the noun thematic, it adds to consistency of description and allows hearing the author's voice and competent placement of major and minor facts of the story.

Adding a final touch to the article, we would also like to express the following academyoriented idea. In classroom practice, apart from granting reliable quantitative data, corpora also provide access to authenticity of the language-in-use. Learners will discover typical collocations that bridge the gap between lexis and grammar and, if necessary, succeed in finetuning selection of specific subject-based samples. Corpora help explore context sensitivity and discursive variation of language phenomena. It means that corpus analysis grammar-wise must be seen as an effective tool raising credibility of fundamental rules, on the one hand, and outlining the territory of possible usage-based amendments, on the other. Both will help master language skills and help raise more knowledgeable language users.

\section{REFERENCES}

1. Barkhudarov, L.S. (2009). Modern English morphology. Moscow: Librocom (in Russian).

2. Biber, D. et al. (1999). Longman Grammar of spoken and written English. Harlow: Pearson.

3. British national corpus. Retrieved from http://corpus.byu.edu/bnc/_(accessed: 12 June, 2019).

4. Carstairs-McCarthy, A. (2002). An introduction to English morphology. Edinburgh: Edinburgh University Press.

5. China's history of extraordinary rendition. $B B C$ News. Retrieved from https://www.bbc.com/news/world-asia-china-48634136 (accessed: 15 June, 2019).

6. Corpus of contemporary American English. Retrieved from http://corpus.byu.edu/coca/ (accessed: 12 June, 2019).

7. England's big picture: sharing images of the nation. $B B C$ News. Retrieved from https://www.bbc.com/news/uk-england-48580727 (accessed: 15 June, 2019).

8. Gordon, E.M., \& Krylova, I.P. (1986). A grammar of present-day English. Moscow: Vysšaya Škola.

9. Greenbaum, S. (1996). The Oxford English grammar. Oxford University Press. 
10. Huddleston, R., \& Pullum, G.K. (2002). The Cambridge grammar of the English language. Cambridge: Cambridge University Press.

11. Ivanova, I.P., Bourlakova, V.V., \& Pocheptsov, G.G. (1981). Theoretical grammar of present-day English. Moscow: Vysšaya Škola (in Russian).

12. Quirk, R. et al. (1985). A comprehensive grammar of the English language. Longman.

13. Reznik, R.V., Sorokina, T.S., \& Kazaritskaya, T.A. (1999). 90 basic rules of English grammar with exercises for school students and university applicants. Moscow: Drofa (in Russian).

14. Swan, M. (1995). Practical English usage. Oxford: Oxford University Press.

15. Trump's problem isn't Mexico. It's Central America, and it's getting worse. CNN News. Retrieved from https://edition.cnn.com/2019/06/14/politics/trump-mexico-centralamerica-intl/index.html_accessed: 14 June, 2019).

16. The vandalized Little Mermaid. BBC Culture. Retrieved from http://www.bbc.com/culture/story/20170602-the-vandalised-little-mermaid (accessed: 10 June, 2017).

17. U.S. escalates online attacks on Russia's power grid. The New York Times. Retrieved from https://www.nytimes.com/2019/06/15/us/politics/trump-cyber-

russiagrid.html?action=click\&module=Top\%20Stories\&pgtype=Homepage $($ accessed: 12 June, 2019).

18. Vorontsova, G.N. (1960). Essays on English grammar. Moscow: Literature in Foreign Languages (in Russian). 